OPEN ACCESS

Edited by:

Scott Bremer

University of Bergen, Norway

Reviewed by:

Stephanie Kay Moore,

Northwest Fisheries Science Center,

United States

Juan Baztan,

CEARC, Marine Sciences For

Society, France

${ }^{*}$ Correspondence:

Jennifer Joy West

j.j.west@cicero.os/o.no

Specialty section:

This article was submitted to Climate Risk Management,

a section of the journa

Frontiers in Climate

Received: 01 December 2020 Accepted: 13 April 2021

Published: 14 May 2021

Citation:

West JJ, Järnberg L, Berdalet E and Cusack C (2021) Understanding and Managing Harmful Algal Bloom Risks in a Changing Climate: Lessons From the European CoCliME Project. Front. Clim. 3:636723.

doi: 10.3389/fclim.2021.636723

\section{Understanding and Managing Harmful Algal Bloom Risks in a Changing Climate: Lessons From the European CoCliME Project}

\author{
Jennifer Joy West ${ }^{1 *}$, Linn Järnberg ${ }^{2}$, Elisa Berdalet ${ }^{3}$ and Caroline Cusack ${ }^{4}$ \\ ${ }^{1}$ Center for International Climate Research - Oslo, Oslo, Norway, ${ }^{2}$ Stockholm Environment Institute, Stockholm, Sweden, \\ ${ }^{3}$ Institute of Marine Sciences (ICM-CSIC), Barcelona, Spain, ${ }^{4}$ Ocean Climate and Information Services, Marine Institute, \\ Galway, Ireland
}

This paper discusses the conceptual and methodological challenges to co-developing high-quality and transferable knowledge to understand and manage harmful algal bloom $(\mathrm{HAB})$ risks as part of adaptation to changing aquatic ecosystems in Europe. Global $\mathrm{HAB}$-climate change research efforts to date have focused on enhancing the credibility of scientific knowledge by conducting basic scientific research aimed at understanding the physical and biogeochemical drivers and mechanisms shaping HAB dynamics in order to predict their occurrence and prevent their societal and ecological impacts. However, the rapid and interconnected changes occurring in marine ecosystems worldwide necessitate a simultaneous shift toward enhancing the salience, legitimacy, usefulness, and usability of this knowledge for decision-making. To address this need, we present and discuss empirical findings from the marine-focused CoCliME project, which set out to co-develop user-oriented climate services to support HAB risk mitigation and adaptation in European coastal regions. We present lessons learned in relation to four areas of project implementation, across five regional cases, that emerged as essential for enhancing the quality of knowledge for managing HAB-climate risks: (1) Engaging stakeholders to understand their knowledge, experiences, interests and concerns; (2) Co-developing a shared terminology and framing of the "HAB-related problems"; (3) Advancing scientific understanding of drivers and interactions shaping HAB-climate risks and; (4) Co-producing prototype services that integrate social and HAB-climate data and knowledge to support decision-making. We find that efforts to reduce scientific knowledge gaps and uncertainties about HAB-climate linkages (efforts to enhance credibility), while important, risk overlooking key aspects of knowledge co-production and application that are necessary to render this knowledge more salient, legitimate, useful, and usable. Understanding the multi-risk decision-making context within which societal stakeholders appraise HAB and climate change risks and approaching knowledge co-production as a learning process, are vital lessons learned in this respect. Drawing on project learning, we highlight key priorities for enhancing the societal relevance and impact of HABs-climate research during the UN Decade of Ocean Science for Sustainable Development.

Keywords: harmful algal blooms, risk management, climate services, coastal adaptation, Europe 


\section{INTRODUCTION}

Climate change and anthropogenic pressures are modifying the world's ocean in an unprecedented manner (Pörtner et al., 2019). Increasing atmospheric and ocean temperatures, more persistent water column stratification, ocean acidification, and human induced eutrophication are already impacting coastal ecosystems (Bindoff et al., 2019; Pörtner et al., 2019). And while the long-term and interactive impacts of these trends are difficult to assess, if left unchecked, they are likely to cause major changes to marine ecosystem functions, with corresponding adverse ecological and societal consequences for regions that depend on coastal and marine environments and the economic, social and cultural values and service they support (Claudet et al., 2020). As recognized in the EUs Blue Growth strategy and highlighted in numerous national marine strategies, coastal regions, which support close to half (43\%) of the population in EU countries, provide myriad opportunities for enhancing citizens' health, wellbeing and prosperity (European Parliament, 2015). However, these benefits coexist alongside hazards and risks that may be exacerbated by climate and anthropogenic pressures on coastal and marine environments (European Marine Board, 2013).

One of these hazards is the occurrence of harmful algal blooms (HABs), an important indicator of ecosystem health status. Harmful algal blooms are associated with particular combinations of physical, biological and chemical conditions in marine and coastal environments, and can be facilitated by human activities (for example eutrophication and ecosystem destruction). The term $\mathrm{HAB}$ refers to a biological event that occurs in marine, brackish and freshwater systems when certain macro- or micro-aquatic photosynthetic organisms proliferate above reference limits, causing adverse impacts for ecosystems or society (GEOHAB, 2001; Wells et al., 2020). HABs are natural phenomena modulated by anthropogenic, physical, biogeochemical and climatic factors. They are considered a hazard to aquatic ecosystems and many human marine activities including aquaculture, tourism, recreation, and human health due to the negative impacts that may result from the phycotoxins that are produced and/or oxygen limitation that occurs in the water due to the excess biomass when the bloom is active or decays.

Both warming ocean conditions, as well as eutrophication caused by human activities such as agricultural run-off, may favor the development of particular HABs. Yet the complexities in HAB life cycle stages, and biochemical and physical interactions involved indicate that the scientific community has yet to unravel the particular climate and non-climatic drivers modulating $\mathrm{HAB}$ dynamics (Gobler, 2020). Research suggests that shifting climatic conditions are influencing the biogeographic distributions and abundances of some $\mathrm{HAB}$ species and the temporal and spatial extent of blooms (Wells et al., 2020). The 2019 IPCC special report on the ocean states with high confidence that an increase in coastal HAB events has occurred in many parts of the world since the 1980s (Bindoff et al., 2019; Pörtner et al., 2019). Although regional efforts to reduce nitrogen run-off have been partially successful at controlling eutrophication in areas such as the Baltic Sea region, there has been a notable increase in reports of prolonged $\mathrm{HAB}$ events associated with marine heat waves in different parts of the world in recent years. Such marine heat waves are expected to increase as the climate continues to warm due to continued anthropogenic greenhouse gas emissions (e.g., Di Lorenzo and Mantua, 2016). For example, blooms of the neurotoxin-producing diatoms, Pseudo-nitzschia australis, such as that which coincided with a prolonged marine heatwave in the Pacific Northwest USA in 2015, are becoming more common, with major ecological and economic consequences for marine wildlife and resources, and communities that depend on them (McCabe et al., 2016; Trainer et al., 2020a and references therein). Strong alterations of the atmospheric and oceanic circulation dynamics in the southeastern Pacific Ocean, likely related to climate change, were also linked to massive HABs dramatically affecting salmon and shellfish aquaculture in 2016 (Trainer et al., 2020b). Of further concern and as highlighted by the 2019 IPCC report, many coastal communities will be exposed to future $\mathrm{HAB}$ risks, especially in areas where $\mathrm{HAB}$ monitoring is poorly implemented (Bindoff et al., 2019 and references therein).

The increasing prevalence of major $\mathrm{HAB}$ events in recent years corresponding with marine heatwaves (e.g., McCabe et al., 2016; Roberts et al., 2019) and other extreme events highlights the need for more robust and impactful HAB risk mitigation and adaptation strategies on a regional and global scale. Yet to date, there remains a paucity of high-quality and actionable knowledge to support $\mathrm{HAB}$ risk assessment and management in the face of climate change (GlobalHAB, 2017; Ritzman et al., 2018). To address this gap, we present and discuss conceptual and methodological challenges and lessons learned within the European research project "Co-developing Climate Services for Adaptation to Changing Marine Ecosystems" (CoCliME). This transdisciplinary project constituted a collaboration between natural and social science researchers and societal stakeholders from seven European countries across six European coastal regions and set out to enhance the co-production, integration and uptake of high-quality knowledge to support $\mathrm{HAB}$ impacts assessment, risk mitigation and adaptation strategies in European coastal waters in the face of climate change.

\section{Harnessing High-Quality Knowledge for Adaptive Governance in European Coastal Regions}

The transdisciplinary approach taken in CoCliME reflects increasing calls to improve the link between high-quality scientific outputs from marine based research and societal decision-making needs (Stenseth et al., 2020). Attending to the multiple drivers and consequences of coastal and marine ecosystem dynamics and changes-including those that contribute to HABs-requires that environmental decisionmakers have access to the necessary knowledge to manage complex risks and changes in a flexible and adaptive manner (Cvitanovic et al., 2015). An adaptive management approach has been identified as vital for navigating these challenges; however, ensuring the necessary knowledge exchange and trust between scientists and environmental decision makers remains a significant obstacle (Cvitanovic et al., 2015; Stenseth et al., 
2020). Joint knowledge production processes involving scientists and societal decision-makers-also known as "knowledge coproduction" - is increasingly advocated as a way to bridge the gap between the supply of and demand for scientific knowledge and to render scientific advice more actionable in practice (Lemos et al., 2012). Under the United Nations Decade of Ocean Science for Sustainable Development (2021-2030), for example, there are increasing calls for enhanced collaborations across scientific disciplines, geographic and political borders, and science-policy interfaces in order to improve the credibility, salience, legitimacy, and usability of ocean science (Claudet et al., 2020). It is within this timely context that we present lessons learned within the European CoCliME project, which aimed to address many of these challenges.

A number of authors have described the determinants of "high-quality" knowledge. In their seminal article: "Knowledge systems for sustainable development," Cash et al. (2003) draw on "lessons learned" from a series of cases to describe key qualities that enable knowledge systems to mobilize scientific and technological know-how to solve sustainability challenges. The authors show how success in connecting scientific information to decision-making is fundamentally linked to whether and how this "information is perceived by relevant stakeholders to be not only credible, but also salient and legitimate" (Cash et al., 2003, p. 8086). According to the authors, "credibility"... [refers to] "the scientific adequacy of the technical evidence and arguments" while "salience" refers to the extent to which the information that is produced meets the needs of targeted decision makers. "Legitimacy" has to do with the extent to which the production of knowledge, information or technology is inclusive and respectful of stakeholders' different values and beliefs and whether it is "unbiased in its conduct, and fair in its treatment of opposing views and interests" (Cash et al., 2003). Usefulness is defined by Lemos and Morehouse (2005, p. 63) as the extent to which knowledge and information are "provided in forms and at temporal and spatial scales that fit with user practices and needs." The related term of usability refers to whether stakeholders can "actually access and use the information in the form that it has been delivered," e.g., whether it is easily accessible online, in the local language of stakeholders, and in layman terms as opposed to scientific jargon (Lemos and Morehouse, 2005).

To date, global research efforts linking HABs and climate change have focused on enhancing the credibility of scientific knowledge through inter alia, conducting basic scientific research on the physical, biogeochemical and other drivers and mechanisms shaping HAB ecological dynamics. However, efforts to enhance the salience, legitimacy, usefulness, and usability of $\mathrm{HAB}$ research in the context of climate change have received comparably less attention. Yet HABs occur in coastal marine socio-ecological systems undergoing multiple sources of environmental, climatic, and socio-political changes, and are themselves driven by a complex interplay between anthropogenic and natural factors operating and interacting across scales. Addressing $\mathrm{HAB}$ risks to society, whether by reducing drivers such as eutrophication, mitigating impacts, or adapting to the consequences of marine ecosystem changes, therefore requires attention to the social, economic and governance-in addition to ecological-contexts that shape human-ocean interactions in particular contexts.

In the sections that follow, we outline the conceptual and methodological challenges we encountered in the project as we strove to generate salient, credible, legitimate, useful, and usable knowledge, information and services to support HABclimate risk mitigation and adaptation activities in diverse geographic and sectoral contexts. Section Materials and Methods introduces the CoCliME project and regional case studies and describes the steps taken to document and synthesize projectwide "lessons learned." Section Results summarizes key lessons learned with respect to four areas of project implementation that correspond to the five knowledge quality criteria. Here we provide project-wide and case-specific examples of the main encountered challenges and our efforts at addressing them. Section Summary of Findings and Implications for the UN Decade of Ocean Science discusses the findings in light of the wider literature on knowledge quality criteria, climate and $\mathrm{HAB}$ risk management, and adaptive coastal governance and highlights the relevance of the findings for the UN Decade of Ocean Science for Sustainability. This section concludes with recommendations for enhancing the quality of knowledge and knowledge co-production processes to help society better understand, prepare for and manage $\mathrm{HAB}$-climate impacts and risks in coastal and marine socio-ecological systems undergoing rapid changes where decision-making contexts are characterized by high uncertainties.

\section{MATERIALS AND METHODS}

\section{Conceptual and Analytical Framework}

To address the CoCliME objective of co-producing high-quality and transferable knowledge to help society better understand, prepare for and manage $\mathrm{HAB}$-climate risks, we employ a conceptual and analytical framework that describes and links "lessons learned" within four key areas of project implementation to the five "knowledge-quality criteria" of salience, credibility, legitimacy, usefulness, and usability (described in section Harnessing High-Quality Knowledge for Adaptive Governance in European Coastal Regions) that have been identified as important pre-conditions for creating inclusive, robust, policyrelevant and actionable environmental research (Cash et al., 2002, 2003; Lemos and Morehouse, 2005). Specifically, our analysis focuses on lessons learned in relation to (1) Engaging stakeholders to incorporate their knowledge, experiences, interests and concerns (legitimacy); (2) Co-developing a shared terminology and framing of the "HAB-related problems" (salience); (3) Advancing scientific understanding of key drivers and interactions shaping HAB-climate risks (credibility) and; (4) Co-developing prototype services that integrate social and HABs-climate data and knowledge to support decision-making (usefulness and usability). The four areas correspond to key research objectives and activities that emerged as essential for improving the quality of knowledge for understanding and managing HAB-climate risks across five European regional cases (described further below). Our analyses are framed by a hybrid conceptual framework that draws on insights from the literature 
on knowledge-quality criteria and discusses their relevance for $\mathrm{HAB}$-focused climate services and HAB risk management and adaptive coastal and marine governance.

Since CoCliME investigated both the social and ecological dimensions of HAB-climate risks, "vulnerability" and "adaptation" in this article encompass both the ecological and social dimensions of these terms, while recognizing that they are understood and applied somewhat differently by natural and social scientists and in the fields of HABs and climate change research (see section Co-developing a Shared Terminology and Framing of the "HAB-Related Problems"). We therefore employ a broad definition of "vulnerability" that refers to the suite of factors that may render coastal and marine ecosystems, communities and associated sectors susceptible to sustaining harm from climate change, HABs, and their interactions. Similarly, and building partly on the IPCC (2014) definition of adaptation, in CoCliME, "adaptation" refers to socially- as well as biologically-adaptive strategies and actions taken in response to or anticipation of $\mathrm{HAB}$ and/or climate-related risks in order to moderate or avoid harm and/or exploit beneficial opportunities (see e.g., Field et al., 2014, p. 40). In the sense used in this paper, adaptation therefore also encompasses $\mathrm{HAB}$ risk prevention and mitigation strategies (see, e.g., Kudela et al., 2015). These definitions are consistent with the CoCliME interpretation of coastal and marine environments as constituting "coupled socio-ecological systems" (Whitney et al., 2017).

\section{The CoCliME Project and Regional Case Studies}

The transdisciplinary CoCliME project formed part of the ERA-NET Consortium "European Research Area for Climate Services," (ERA4CS), which was designed to boost the development of efficient climate services in Europe (http://www. jpi-climate.eu/ERA4CS). Under ERA4CS, "climate services" are defined as the "user-driven development, translation and transfer of climate knowledge to researchers and decision-makers in policy and business. This includes knowledge for understanding the climate, climate change and its impacts, as well as guidance in the use of climate knowledge". From the beginning, CoCliME set out to co-develop tailored, proof-of-concept and prototype HAB-climate services and a transferable framework to support HAB-climate risk management and adaptation decision-making in European coastal regions. The project focused on HABs as aquatic phenomena that are driven by a range of environmental (including climate) and anthropogenic factors, and their associated impacts on water quality, seafood safety, and different socio-economic sectors. To date, HAB-focused climate services remain in their infancy. For this reason, this pilot project drew upon and combined expertise from diverse scientific disciplines and intensive stakeholder dialogues with exploitation of existing data sets toward the goal of co-producing actionable knowledge to support $\mathrm{HAB}$ risk mitigation and adaptation decisions in specific contexts.

Our analysis in this paper draws on lessons learned across five regional coastal cases: the NE Atlantic (Ireland), NE Atlantic (France), Mediterranean, Baltic and North/Norwegian
Seas. Table 1 summarizes the geographic and sectoral focus, key stakeholders consulted and $\mathrm{HAB}$ issues addressed in each regional case. The cases are in turn briefly presented below.

\section{NE Atlantic (Ireland)}

Closures of aquaculture facilities are caused by Pseudo-nitzschia or Dinophysis biotoxin accumulated in filter feeding mussels and mortalities in fish farms are due to anoxic conditions produced by high biomass Karenia blooms. These blooms originate in offshore shelf waters and are carried to the inshore aquaculture sites by ocean circulation dynamics. In CoCliME a numerical physical hindcast and ocean climate model was developed and combined with in-situ biological information to investigate future possible changes and environmental linkages with HABs.

\section{NE Atlantic (France)}

Shellfish aquaculture in the area is threatened by Alexandrium spp. and Dinophysis spp. biotoxin-producing blooms. Research was undertaken on the biological aspects (food web structure) of the Dinophysis spp. that could be modulated by climate change, and on the economic losses of shellfish farm closures caused by the HABs.

\section{Mediterranean Sea}

In summer, recurrent blooms of Ostreopsis spp. are associated with acute respiratory and cutaneous disorders in beach users, workers and coastal inhabitants. Ongoing studies address the ecology, ecotoxicology, toxin aerosolization, epidemiology, economic impacts, and modeling bloom dynamics as a function of climate scenarios.

\section{Baltic Sea}

This semi-enclosed regional sea is characterized by limited wind mixing, low ventilation of deep water and multiannual eutrophication, which results in an excess availability of nutrients in the system. These conditions favor blooms of nitrogen fixing cyanobacteria in summer that cause problems for tourism and leisure activities and potential human health problems.

\section{North/Norwegian Sea}

In this area, the main $\mathrm{HAB}$ threats are posed by fish-killing microalgae (e.g., Chrysochromulina, Pseudo-chatonnella) that cause infrequent but massive mortalities of farmed fish in aquaculture facilities. HABs causing shellfish closures and recalls are also a recurring problem across the region. Research in this area is investigating the environmental conditions driving these blooms toward predicting their future dynamics, considering biogeographic shifts of HAB taxa and HAB risk periods.

\section{The CoCliME Climate Service Co-development Approach}

In CoCliME, co-development of case-specific proof of concept and prototype $\mathrm{HAB}$-climate services was pursued with targeted stakeholders and end-users through an iterative process organized around project-wide "Engagement Points (EP)." The EPs (Table 2) were carefully designed to flexibly pursue co-discovery with relevant stakeholders in each case study in order to tailor and co-develop useful prototype services. 
TABLE 1 | Summary of the CoCliME case studies discussed in this paper, the HAB taxa addressed, the sectors impacted and types of stakeholders consulted.

\begin{tabular}{|c|c|c|c|}
\hline Case study & HAB taxa (impacts) & Sectoral focus & Types of stakeholders consulted \\
\hline NE Atlantic (Ireland) & $\begin{array}{l}\text { Dinophysis spp. (human health) } \\
\text { Pseudo-nitzschia spp. (human } \\
\text { health) } \\
\text { Karenia spp. (fish-killing; } \\
\text { ecosystem health) }\end{array}$ & $\begin{array}{l}\text { Shellfish aquaculture and associated } \\
\text { industries; Regional and local climate } \\
\text { adaptation }\end{array}$ & $\begin{array}{l}\text { Irish shellfish farmers, coastal adaptation } \\
\text { planners, policy-makers and scientists in } \\
\text { government agencies }\end{array}$ \\
\hline NE Atlantic (France) & $\begin{array}{l}\text { Dinophysis spp. (human health) } \\
\text { Alexandrium spp. (human health) } \\
\text { Ostreopsis spp. (human and } \\
\text { ecosystem health) }\end{array}$ & $\begin{array}{l}\text { Shellfish aquaculture associations } \\
\text { and industry; Tourism }\end{array}$ & $\begin{array}{l}\text { French shellfish farmers and regional shellfish } \\
\text { associations; government authorities }\end{array}$ \\
\hline Mediterranean Sea & $\begin{array}{l}\text { Ostreopsis spp. (human and } \\
\text { ecosystem health) }\end{array}$ & Tourism and health & $\begin{array}{l}\text { Health and environmental authorities (France, } \\
\text { Spain); local residents and tourists (France, } \\
\text { Spain); transboundary environmental } \\
\text { organizations (Monaco, France, Italy and Spain) }\end{array}$ \\
\hline Baltic Sea & Cyanobacteria (ecosystem health) & Coastal and marine planning & $\begin{array}{l}\text { Swedish coastal and marine planners and } \\
\text { managers, and county water authorities }\end{array}$ \\
\hline North/Norwegian Seas & $\begin{array}{l}\text { Dinophysis spp. (human health) } \\
\text { Alexandrium spp. (human health) } \\
\text { Chrysochromulina } \\
\text { leadbeateri (fish-killing) }\end{array}$ & $\begin{array}{l}\text { Shellfish and fish farming industries; } \\
\text { Tourism }\end{array}$ & $\begin{array}{l}\text { Fish farmers, fishery authorities, HAB } \\
\text { researchers and aquaculture-related interest } \\
\text { organizations (Norway); Shellfish farmers and } \\
\text { food safety authorities (Norway and Sweden); } \\
\text { Water managers (Sweden); Conservation } \\
\text { NGOs (Germany) }\end{array}$ \\
\hline
\end{tabular}

Table 1 provides an overview of the main types of stakeholders that were consulted in the different CoCliME cases. The EPs acted as a platform for the CoCliME partners to gather stakeholder input, discuss results, and further tailor product development to suit identified user needs. The EP format ranged in style from workshops, semi-structured interviews conducted in person or by telephone, to virtual online and/or one-to-one or structured group meetings and discussions and online surveys. Regular dialogue with key stakeholders was deemed important and carried out through established working relationships, partnerships, and professional forums/channels in many cases. The targeted stakeholders included co-developer partners identified at the start of the project, new co-developers, intermediary or end-user stakeholders identified during the course of the project, and scientific partners internal and external to the project.

\section{RESULTS}

\section{Engaging With Stakeholders to Understand Their Priorities and Define the Focus of HAB-Climate Services}

To ensure saliency and legitimacy, a climate service codevelopment process must take its starting point in thoroughly analyzing stakeholder priorities and decision-making contexts (Buontempo et al., 2017). Discussions and interviews with stakeholders at the start of the project (EP1) revealed that vulnerability and adaptation to and mitigation of HABs risks, are location- and stakeholder-specific and depend on a range of contextual factors. Characteristics of the bloom such as the timing of the onset, and the duration and location of blooms relative to the main periods of economic activity (e.g., during peak tourism season in the Mediterranean Sea, or during the fish growth period from smolts to adults in aquaculture pens in the North/Norwegian Seas), has a significant effect. Economic factors related to business activities that affect vulnerability and adaptive capacity to $\mathrm{HAB}$ risks include the size of firms and levels of integration and/or collaboration across them (with smaller firms typically, though not always, being more vulnerable), the extent of economic diversification across geographic areas, species and markets, the potential for substitution (i.e., sourcing fish or shellfish from other locations), the flexibility of operations (e.g., the potential to move planned maintenance activities to periods of closures, delay harvesting, and the flexibility of the workforce), and the extent of economic support mechanisms such as insurance or other compensation measures in the event of prolonged closures or large-scale mortalities of farmed fish. Technological factors such as access to, and ability to implement, mitigation options, such as raising or lowering fish cages, and the use of physical control methods such as "bubble curtains" (e.g., Gallardo-Rodríguez et al., 2019) also play a role. Finally, aspects related to the social infrastructure, including the extent of local networks and cooperation for monitoring, mitigation, and emergency preparedness and response, shape stakeholders' vulnerabilities, and adaptation to $\mathrm{HAB}$ risks and their ability to mitigate impacts (e.g., Le Bihan et al., 2013; Guillotreau et al., 2017). For example, CoCliME interviews conducted with Norwegian aquaculture stakeholders that were affected by a devastating bloom of Chrysochromulina leadbeateri in northern Norway in 2019 revealed that close cooperation between familyowned salmon farming firms in the affected region was decisive for managing the effects of the bloom.

The perceived importance of $\mathrm{HAB}$ risks, relative to other risks, moreover varies according to the occupational and professional roles and knowledge and background of different 
TABLE 2 | Focus and aims of the project-wide Engagement Points (EP).

\begin{tabular}{|c|c|c|}
\hline EP & Short name & Focus and aims \\
\hline EP1 & "User needs and experiences" & $\begin{array}{l}\text { Document stakeholder knowledge, interests, concerns and needs related to HABs and climate } \\
\text { change risks; enhance CoCliME partner understanding of stakeholder adaptation and mitigation } \\
\text { options and potential need for HAB-climate services }\end{array}$ \\
\hline EP2 & "Ambition with climate services" & $\begin{array}{l}\text { Map existing HAB-climate services and technology readiness levels (TRLs); establish TRL } \\
\text { ambitions; refine stakeholder and scientific focus in the different cases }\end{array}$ \\
\hline EP3 & $\begin{array}{l}\text { "Stakeholder feedback" } \\
\text { Originally entitled: "Future risks and } \\
\text { adaptation options" }\end{array}$ & $\begin{array}{l}\text { Present and discuss preliminary results that could feed into a prototype HAB-climate service with } \\
\text { targeted stakeholders; discuss the format and content of potential services and gather and/or } \\
\text { synthesize social, economic, statistical, ecological and other data needed to develop the service }\end{array}$ \\
\hline EP4 & "Implementation" & $\begin{array}{l}\text { Co-develop, test and/or implement prototype HAB-climate services; identify and discuss } \\
\text { implementation and sustainability opportunities and challenges with stakeholders }\end{array}$ \\
\hline EP5 & "Dissemination and evaluation" & Presenting project results; identify wider dissemination pathways for CoCliME prototype services \\
\hline
\end{tabular}

stakeholders. In cases having shellfish aquaculture as a focus, some stakeholders have extensive experience and well-developed adaptation strategies for dealing with regularly occurring HABs on a seasonal or cyclical basis. In other cases, sporadic, major bloom events that occur with no forewarning and cause massive mortalities of farmed fish are a key concern. Economic risks and impacts from pathogens that cause shellfish mortalities are a more important concern than HABs in some regions while in others, predation by starfish, jellyfish and eider ducks are key concerns. In cases where the linkages between HABs and human health are not obvious or well-established, local residents and tourist stakeholders may not be fully aware of potential $\mathrm{HAB}$ risks.

Stakeholder perceptions and concerns about climate change in relation to $\mathrm{HABs}$ moreover varied widely. Some stakeholders in the NE Atlantic (Ireland) and North/Norwegian sea cases expressed specific concerns about potential risks associated with new invasive HABs species, driven by climate change. Most stakeholders however, noted that climate change is only one among multiple factors driving HABs, and recognize that large uncertainties are involved when trying to project HABs into the future. To meet stakeholder needs and interests, CoCliME researchers had to maintain a high level of flexibility. For instance, in the Irish case, regional policy makers asked specifically for a climate information service in the form of outreach material for local authorities and the public. To accommodate this request, CoCliME activities were realigned, and the scientists worked with the co-developer and a designer to produce graphics and climate information suitable for the target audience. Co-creating outreach material from technical results with the end-user was a helpful exercise and highlighted the importance of addressing end-user's interests and needs and working together to produce useful decision support products.

In summary, experiences in CoCliME suggested that stakeholders have varied understandings, awareness and priorities when it comes to HABs and climate change risks and their management that affect the perceived saliency of a HAB climate service. These factors needed to be assessed thoroughly in a co-design process, where stakeholders' knowledge, experiences, interests, and concerns constituted the starting point for finding the appropriate focus and entry-points for service development.
The EP format in the project was therefore tailored in each case to support co-design and co-development of prototype services at local scales that were differentiated according to case study-specific parameters and stakeholder needs and realities. Stakeholders' varied climate-change perceptions and understandings, $\mathrm{HAB}$ and climate service knowledge, interests and priorities, and their perceived vulnerability and strategies for avoiding, adapting to and managing $\mathrm{HAB}$ risks formed an important backdrop for co-developing a shared terminology and framing of the "HAB-related problems" to be addressed in each case, to which we turn in the section below.

\section{Co-developing a Shared Terminology and Framing of the "HAB-Related Problems"}

Conceptually, "framing" refers to "a process by which actors construct and represent meaning to understand an event, process, or occurrence" (Lugen, 2020, p. 2). The act of framing includes the definition of scientific terminology whereby "individual disciplines and their associated academic networks can be understood as communities of practice which "make meaning" by creating and reinforcing a shared frame around their research topic" (ibid). The framing of scientific problems reflects shared assumptions and values within a scientific community as expressed in research methodologies, hypotheses, and in specific forms of expert language. For example, the term "harmful algal bloom" is essentially a "societal term" (Smayda, 1997) that is species-specific and defined normatively according to what society judges to be "harmful." As a transdisciplinary project involving multiple cases and disciplines and seeking to integrate different forms of scientific and lay expertise, the implicit assumptions, discourses, terminology, language and epistemological, conceptual and methodological approaches employed within and across the project differed substantially. Differences in the terminology and scientific approaches employed within and across the consortium were not always openly discussed or communicated at the start of the project. It moreover became clear early on that scientist and stakeholder understandings and framings of the importance of HABs and climate change for decision-making and salient problems to be addressed differed substantially in some cases. This led to 
plural understandings of how to approach climate service coproduction and created some challenges for integrating and connecting knowledge and data at later stages of the project.

\section{Language and Terminology}

Two examples illustrate the diversity of ways in which CoCliME scientists approached key language and terminology. The first example concerns the terms "mitigation," "adaptation, "adaptive capacity" and "resilience." The term "mitigation" in a HAB context refers to human actions taken to reduce the ecological or societal impact of a HAB event, while for climate change, it refers to efforts to reduce local and global emissions of greenhouse gases. Examples of HAB mitigation activities at the firm level include moving fish cages away from a patchy high biomass bloom or transferring shellfish into depuration tanks to remove accumulated biotoxins that can harm consumers if eaten. Governments may facilitate HAB mitigation through the provision of subsidies or compensation measures to individual firms that limit the potentially devastating local consequences of major bloom events.

From a social science perspective, adaptation, adaptive capacity and resilience refer to how an individual, a company or firm, a community, sector or even a country acts to achieve health and well-being in the face of complex socio-economic and environmental change processes (Smit and Wandel, 2006). Societal vulnerability, adaptive capacity, and resilience are interlinked, context-specific, socially differentiated, and shaped by a range of social, political, institutional, economic and environmental aspects and interactions (Engle, 2011). Since coastal and marine environments constitute "coupled socioecological systems," there is a need to incorporate and address both the ecological and social dimensions of these terms (Whitney et al., 2017).

From an ecological point of view, "adaptation" and "adaptive capacity" refer to biologically adaptive strategies to ensure survival and reproduction of the organisms within any ecosystem (Whitney et al., 2017). For example, the microscopic biotoxinproducing microalga Dinophysis is a predator that feeds on other microorganisms (ciliates called Mesodinium rubrum), which in turn feed on smaller microflagellates such as Teleaulax amphioxeia. Dinophysis blooms are dependent on food sources (prey) that are sensitive to marine environmental factors that vary with changes in physical parameters (e.g., temperature, $\mathrm{pH}$ and light). Thus, in CoCliME, laboratory studies were conducted with these microorganisms to explore their potential adaptive capacity to climate change scenarios. Related to the ecological definition of "adaptation" is the concept of "ecological niches," which are the ensemble and ranges of environmental conditions (physical and biogeochemical) that define where an organism has adapted to live.

A second example is the term "climate services," a relatively new term for which there are a number of definitions operating in research, policy and practice. While CoCliME adopted the definition of climate services employed by the ERA4CS (see section The CoCliME Project and Regional Case Studies), natural and social scientists in the project interpreted the term depending on their particular perspectives. For physical oceanographers focused on open sea environments such as the Baltic Sea and the North Seas, climate services consisted of providing hindcasts and forecasts of the marine environmental properties that influence the occurrence of high biomass HABs. In this case, well-organized and technically supported numerical modeling tools were necessary to develop the climate services. In the NE Atlantic (France) case study, the target for climate services was Dinophysis, a highly toxic HAB species, that even at low biomass can contaminate shellfish and cause shellfish poisoning if consumed by humans. For the natural scientists in this case, a key focus was on filling knowledge gaps on small scale ocean processes affecting the bloom and clarifying the adaptation of essential Dinophysis food web components to changing light, temperature and $\mathrm{pH}$ conditions (Gaillard et al., 2020). Knowledge at this small scale can be combined with physical oceanographic numerical modeling of future scenarios to progress climate service development (Ralston and Moore, 2020). On the social science side, economists worked to develop a harmonized database of shellfish farming closures in order to assess the economic impacts of the closures. Both types of data are needed in order to provide actionable information to decision makers working to reduce the economic and health impacts of Dinophysis-related shellfish farming closures in the area.

\section{Establishing Salience: Understanding the Reason for Concern}

One of the key challenges we faced as a project from a scientific point of view was to develop HAB-related data products that contribute to services that can help the end user(s) to make decisions. On the natural science side, the entry-point for service development was on addressing knowledge gaps that prevent connecting and integrating information about HABs with information about climate change. On the social science side, interactions with stakeholders during engagement points generally revealed that HABs are only one part of a complex multi-risk picture and may not be the most important or impactful risk that they need to consider in their decision-making.

Several examples from stakeholder engagements undertaken during the project highlight this point. For instance, shellfish and fish farmers are usually concerned with factors that affect mortality of shellfish or fish since these lead to direct losses that cannot be recuperated by delaying harvesting, and often cannot be foreseen through monitoring or other efforts. Other factors affecting mortalities that were identified by shellfish and fish farmers in the North Sea and Norwegian Sea case study included marine pathogens, oxygen depletion, predation by other species (shellfish), sea lice and other diseases (in the case of fish). In the Baltic Sea case study, it became clear that HABs are one aspect or indicator of ecosystem health and water quality that need to be considered by marine spatial planners, alongside numerous other factors. For food safety authorities, HABs are one aspect of monitoring and regulation of harmful substances in seafood consumed by people in Europe and globally (see for example the European Food Safety Agency webpage, https://www.efsa.europa.eu/en). In addition to wellknown seafood poisoning risks caused by harmful algae, care 
is taken to protect consumers from emergent poisonings, such as those associated with the tropical genus Ostreopsis, which produces potent toxins that can be transferred through the food web and can cause respiratory and cutaneous irritations on beach users, inhabitants and workers exposed to marine aerosols during the summer vacation period (e.g., Berdalet et al., 2016; Vila et al., 2016 and references there in) with implications for both human health and tourism in affected regions. The challenges for the scientific stakeholders involved in Ostreopsis monitoring in the Mediterranean Sea case study in CoCliME included adequately informing the population without causing alarm, while also communicating with health authorities to distinguish between microalgae-induced respiratory problems and similar disorders caused by virus or bacteria, which may require specific types of treatment. Like other HABs, Ostreopsis blooms moreover appear to be driven by a combination of climate (e.g., ocean temperature-related) factors as well as alterations of the coastal zone due to factors such as infrastructure development in coastal areas and beach erosion caused by violent storms. For health authorities, bacteria and chemical contamination due to sewage and agricultural runoff are further concerns which may increase in the future due to climate change-induced alterations in the frequency and intensity of extreme weather.

In Ireland, the Climate Action Regional Office (CARO) with whom CoCliME scientists partnered is responsible for coordinating regional climate action and providing guidance, advice and support to local governments and the communities they serve on national climate change policy. During interviews and discussions, they explained that coastal communities in Ireland are especially in need of climate services that can assist them to adapt to extreme weather events such as floods and storms, as well as longer-term processes such as sea-level rise and associated impacts such as submergence, flooding, shoreline erosion, salinization and wetland change. Since local authorities provide hundreds of services ranging from roads, planning, housing, economic and community development, environment, recreation, and amenity services, libraries and fire services, HABs were not considered by the CARO to be a primary concern for communities. However, community adaptation strategies are currently being developed under Ireland's Climate Adaptation Framework, with a view to identifying what functions are at risk from climate change and what action is needed to adapt and build resilience. This requires an understanding of the multiple risks and impacts of climate change across many categories (social, economic, cultural, infrastructure, ecosystems etc.) with HABs constituting one of the many hazards to consider.

Our findings thus point to the need to take a more holistic approach to the concept of "service development" as encompassing more than HABs. This resonates with scholarship on the links between climate change and societal vulnerability and adaptation, which has long recognized that people are not vulnerable or adapting to climate change risks independent of other hazards or risks. Climate change is only one type of change and "stressor" (and not always the most important one) to which people are responding Leichenko and O'Brien (2000).

In summary, in CoCliME scientists and stakeholders brought different conceptual and methodological entry-points, expertise and concerns to the table in seeking to study and address the complex interface between climate change and HABs. The plural definitions and ambiguity in the concepts and language used by scientists and stakeholders affected how HAB-climate change risks were understood, framed and approached scientifically and in practice. The fact that HABs are one of many challenges facing operational stakeholders and coastal decision-makers poses particular challenges for efforts to co-design services that link the two.

\section{Advancing Scientific Understanding of Drivers and Interactions Shaping HAB-Climate Risks and Societal Impacts}

CoCliME experiences highlighted that, in general, transdisciplinary research linking physical climate, marine ecology, and social science approaches with information about salient societal information needs can guide the process toward co-developing credible HAB-climate services. CoCliME aimed to co-develop HAB-related climate services and thus needed to anticipate future trends of HABs and their societal and ecological impacts. The partners identified existing tools and knowledge that could contribute to co-develop a wide range of prototype $\mathrm{HAB}$-related climate products and services (see Table 3). Overall, efforts to generate a credible knowledge base resulted in important scientific advancements. However, several critical knowledge gaps remain, including the link between environmental changes and $\mathrm{HAB}$ responses, and the interactions between HABs and essential climate variables. These gaps are linked to the complex environmental interactions of HAB dynamics, limitations in data availability, and lack of statistical and modeling expertise in the project. These challenges and their implications for the co-development of credible HAB-climate services are discussed below.

\section{Gaps in Basic Knowledge to Determine HAB Species Ecological Niches}

Despite increasing scientific knowledge, there remain large uncertainties about the precise linkages between climate change and specific HABs due to the complexity of biogeochemicalclimate interactions for different $\mathrm{HAB}$ types and locations (Wells et al., 2015). In many cases environmental drivers of HABs are not fully understood (e.g., see Hallegraeff, 2010; Wells et al., 2015 and references therein). While underlying conditions necessary for $\mathrm{HAB}$ events are often described in the literature (e.g., Raine, 2014), it is acknowledged that the presence of such "HAB suitable" conditions may not lead to a bloom event. There is also a miss-match between observed $\mathrm{HAB}$ numbers and recorded toxicity that is in some cases attributed to differences in the production of biotoxin by different phytoplankton species of the same genus, or toxic and non-toxic strains within a species (e.g., Trainer et al., 2012), or environmental control (temperature, nutrient availability) of biotoxin production. In other cases, the reasons are still poorly understood. Phytoplankton can have a rapid (within days) response time to changing environmental conditions. It is therefore reasonable to compare HABs to environmental 
TABLE 3 | CoCliME prototype HAB-related climate products and services.

\begin{tabular}{|c|c|}
\hline Cases & CoCliME products and services \\
\hline NE Atlantic (Ireland) & $\begin{array}{l}\text { Scientific data products and hindcast and ocean climate } \\
\text { models (SW Ireland) to share with researchers } \\
\text { (intermediary service) } \\
\text { CoCliME co-created graphical illustrations to be used by } \\
\text { the project partners and co-developers to raise } \\
\text { awareness about ocean climate change and HABs as a } \\
\text { downstream service for policy makers and the } \\
\text { general public }\end{array}$ \\
\hline NE Atlantic (France) & $\begin{array}{l}\text { Harmonized database on shellfish farm closures and } \\
\text { economic impacts } \\
\text { Transnational ocean particle tracking modeling in the NE } \\
\text { Atlantic which can be made available to future projects } \\
\text { Biological model on Dinophysis prey available to } \\
\text { modelers } \\
\text { HAB datasets incorporated into REPHY monitoring }\end{array}$ \\
\hline $\begin{array}{l}\text { North/Norwegian Seas } \\
\text { and Baltic Sea }\end{array}$ & $\begin{array}{l}\text { Hindcast and ocean climate projections for the Baltic } \\
\text { Sea } \\
\text { Analyses of cyanobacteria time series data } \\
\text { Tools for analyzing and visualizing model and } \\
\text { observational results (Python and R-scripts) } \\
\text { Molecular HAB detection training for national monitoring } \\
\text { programme scientists } \\
\text { Proposed method to include harmful algae blooms in a } \\
\text { marine spatial planning tool (Symphony) } \\
\text { Proposed linkage of HAB monitoring and development } \\
\text { of an early warning system for the Kattegat-Skagerrak } \\
\text { region } \\
\text { Co-development of a national website (one-stop shop) } \\
\text { to connect and share HAB-related observations and } \\
\text { early warning information (Norway) }\end{array}$ \\
\hline Mediterranean & $\begin{array}{l}\text { CoClimer package (package for the statistical description } \\
\text { and analysis of HAB-forming organisms time series) } \\
\text { Ostreopsis dataset in the Catalan coast } \\
\text { CoCliME Ostreopsis climate service v0.1 (Predicted } \\
\text { maps of present and future abundances of Ostreopsis cf } \\
\text { ovata along western Mediterranean shores) } \\
\text { Co-design of and training for a Mediterranean Ostreopsis } \\
\text { monitoring programme }\end{array}$ \\
\hline
\end{tabular}

conditions at the same point in time and environmental conditions several days prior to $\mathrm{HAB}$ observations. It is also possible for $\mathrm{HABs}$ to have a slower response time or that preSpring bloom environmental conditions have significant effects on whether HABs will develop later in the year or not. It is also possible that there is a mismatch between the location where HABs are observed and the environmental drivers. This means that underlying environmental conditions that stimulate $\mathrm{HAB}$ growth are missed at unmonitored sites where HABs develop unobserved before being transported in ocean currents to the monitoring sites where they are recorded (e.g., Anderson et al., 2019).

\section{Limitations of Data Availability}

High quality, comparable, long-term environmental and HAB data are essential to assess and manage $\mathrm{HAB}$ risks over a range of timescales. HAB events are generally only recorded at fixed locations such as at shellfish harvesting sites or popular tourist destinations. Fluctuations in marine algae and plankton are a natural-and also essential-part of marine ecosystem dynamics and food web structure. Toxic or harmful algae may be present in marine ecosystems, but go undetected, or may not result in an algal bloom that is associated with negative societal impacts, complicating detection and assessment of ecological impacts. Due to limited resources, $\mathrm{HAB}$ records might only be available seasonally, at few sites and at a fixed water depth or as depth integrated samples. Data on ecological impacts are normally not recorded in a systematic way; surveys are generally only carried out on an ad-hoc basis, in response to HAB events that have caused economic impacts (closures of shellfish harvesting sites, death of farmed fish), with fragmented reports and accounts of the ecological impacts. Key drivers of phytoplankton succession, such as nutrients, prey and competition are missing for many case studies. Monitoring of HABs was insufficient in some CoCliME regions (e.g., enhanced monitoring was needed to address an exceptional fish killing bloom in Norway). While the partners worked with policy makers to address these issues, the important lesson here is that individual champions and formalized, cross-border collaboration and funding are required to sustain such activities in the long term. Similarly, a lack of historical high quality sustained ocean observing data needed to do trend analysis posed challenges to generating credible data in some cases. A lack of long-term observational data can lead to flawed decision-making due to insufficient understanding of natural and anthropogenic-imposed variability over time (Stenseth et al., 2020). The relatively short time series inhibited progress in the data analyses activities in all of the cases. Climate change is measured over centuries, with at least 30 years of data needed to calculate climatological averages, while most biological HAB datasets are only 20 years in length. While some trends were observed, the high interannual biological variability made it difficult to identify statistically significant trends in many of the available datasets. A substantial share of the project time was therefore spent on gathering baseline information on environmental, social and climate variables to create credible knowledge about the links between environmental change and HABs.

\section{Limited Statistical and Modeling Expertise and Short Duration of the Project}

Lack of numerical and statistical experts, and bottlenecks related to accessing modeled data in the right format for biologists to use in data analyses posed additional challenges. European downscaled ocean climate models were, unfortunately, unavailable from data repositories at the start of the CoCliME project. This inhibited progress in some areas as only a few partners had funds to develop ocean models for specific regions. Fortunately, more downscaled ocean models are becoming available in this area of research; this is welcomed by the community. The modelers in the project responded to a need expressed by the biologists to develop a data extractor to condense numerical model information into usable formats. A CoClime expert hosted training courses and shared an application to facilitate time series analyses. However, time limitations within the project proved to be one of the biggest challenges in CoCliME, as it takes time to do basic scientific research. While this inhibited progress in areas of basic science 
that are critical to advancing $\mathrm{HAB}$-climate services, the modeling approaches used in $\mathrm{HAB}$ projections were shared between partners in order to help build capacity within organizations and the information generated will be made publically available to enable learning in the wider scientific community. In addition, CoCliME was involved in documenting the best practice on how to create a weekly HAB bulletin to assist other regions (Leadbetter et al., 2018; Pearlman et al., 2019).

\section{Challenges in Assessing HAB Impacts}

$\mathrm{HAB}$ socio-economic impacts include both tangible and intangible economic, and non-economic impacts related inter alia to shellfish and/or beach closures and mortalities of farmed fish (Trainer, 2020). To date, a lack of comparative methodologies to study these impacts, which are often case-specific, complicates efforts to derive more general lessons about the costs of HAB events and the costs and benefits of measures to mitigate these impacts (ibid). While intangible and non-economic impacts of HABs are less studied and may be more difficult to assess quantitatively, recent studies indicate that they may nonetheless be substantial, and may include impacts such as psychological and mental stress, loss of traditional ways of life, recreational opportunities, spiritual and aesthetic experiences in nature, sense of individual and collective identities and cultural attachment and place-belonging (Ritzman et al., 2018; Willisa et al., 2018). The economic and social impacts of shellfish closures may extend beyond coastal and marine-based harvesting activities and into other sectors, such as tourism.

In terms of human health impacts, many $\mathrm{HABs}$ produce biotoxins that affect human health through food-borne poisonings, or exposure to aerosols, or direct contact with water (as indicated above). While most HABs are natural phenomena and unavoidable up to a certain point, their impacts on human health can be prevented. However, misdiagnosis and underreporting are common concerning HAB-related health impacts. Emerging biotoxins are moreover less well-characterized and constitute new challenges.

\section{Assessing and Communicating HAB-Climate Risks}

Assessing and communicating HAB-climate risks to the public and determining the vulnerability and adaptive capacity of various societal actors, sectors and communities to coupled HAB-climate risks is complicated by several factors. First, despite increasing scientific knowledge, there remain large uncertainties about the precise linkages between climate change and specific HABs due to the complexity of biogeochemicalclimate interactions for different HABs and locations (Wells et al., 2015). This limits the informative value of marine ecosystem- or climate indices or indicators in predicting the exposure of societal actors to climate-induced changes in the frequency, intensity or spatial occurrence of HABs. Second, the presence of potentially toxic $\mathrm{HAB}$ species or environmental conditions favoring their presence, does not necessarily translate into observable ecological, social or economic impacts. Third, the potential for direct and indirect economic, health, and/or intangible impacts of HABs are mediated by how HAB risks are determined scientifically and legally (e.g., biotoxin threshold levels above the EU regulatory limits) as well as how such risks are communicated, experienced and perceived by different actors. For example, precautionary measures taken to reduce the potential impact of HABs on public health, such as closure of beaches in areas where there is a projected threat, can have major economic impacts on tourism, irrespective of whether the HAB risk materializes. In a similar vein, but, with respect to health, residents may choose to ignore warnings about potential shellfish poisoning or beach closures in their area, due to subjective perceptions of vulnerability and higher levels of risk tolerance. These examples illustrate that there is not a simple, linear or causal relationship between the detection and communication of $\mathrm{HAB}$ risks, actions taken to avoid, reduce or adapt to them, and efforts to evaluate HAB impacts.

In summary, we find that sustained investments in longterm HABs and environmental modeling, in securing social and economic expertise, and in training and capacity building to connect different communities of practice, are a prerequisite for co-developing credible and actionable HAB-climate services. The fact that large scientific uncertainties remain regarding the biophysical drivers of HABs, the outcomes of different climate scenarios, and the societal vulnerabilities, impacts, adaptive capacities and risk perceptions of particular communities and sectors, highlights that renewed investments are needed in transdisciplinary $\mathrm{HAB}$ science and in continued maintenance and optimization of existing $\mathrm{HAB}$ monitoring programmes to provide long term datasets and test the validity of models (Ralston and Moore, 2020). Enhancing understanding of the risk perceptions, institutional, business and decision-making contexts and adaptation processes of different end-user groups further requires dedicated social science expertise and is necessary in order to ensure that salient, credible and timely advice is included in $\mathrm{HAB}$ and climate risk mitigation and adaptation plans.

\section{Co-developing Prototype Services That Integrate Data and Knowledge to Support Decision-Making}

Co-developing prototype services that incorporate and integrate different sources and types of data and knowledge in order to inform $\mathrm{HAB}$ risk mitigation and adaptation decisions in diverse contexts posed particular challenges in CoCliME. Below, we discuss key lessons learned relating to scientific integration, knowledge co-production and service co-development and propose potential strategies for making HAB-climate information more useful and actionable.

\section{Integration Across Disciplines, Cases, and Types and Scales of Data}

CoCliME drew upon and sought to combine a wide range of natural and social science expertise covering oceanography, marine biology, ecology, numerical and statistical modeling, chemistry, economics and geography as well as combining traditional, science-focused, and applied research organizations. The diversity in conceptual and methodological approaches and epistemologies with respect to applied, vs. basic research was substantial, and posed challenges at times to meaningful 
integration. The CoCliME project design was moreover highly ambitious in targeting numerous $\mathrm{HAB}$ taxa over several geographic regions, with multiple sectors, stakeholders and impact areas to address. The diversity of HAB taxa and their ecological niches and societally relevant impact areas necessitated approaching the study of HABs from multiple perspectives and at different scales simultaneously. Accordingly, the events and processes studied within the project ranged from adaptive cellular processes (namely, biotoxin and cell growth) of individual HAB species to environmental changes (defining ecological niches), to the impacts of HAB events on ecosystems, local and regional economies and human health. Exploratory investigations were in some cases also carried out into how society may adapt to changing marine ecosystems, considering local, regional and global-scale ocean climate projections and their uncertainties. Finally, because the ocean has no borders, some HABs were analyzed from a transboundary perspective where similarities and differences in administrative, ecological, physical, sectoral, or other boundaries had to be considered in order to mitigate potential $\mathrm{HAB}$ and climate change impacts and their interactions. While addressing multiple objects of study increased the salience of the research, this context-specific approach prevented making systematic comparisons across cases.

As highlighted in section Advancing Scientific Understanding of Drivers and interactions Shaping HAB-Climate Risks and Societal Impacts, a lack of comparable, long-term data, and difficulties in accessing and processing data in some cases posed further challenges to knowledge integration. Existing historical data sets come with a legacy in that they were collected for a specific purpose (e.g., EC Directive-driven national biotoxin and $\mathrm{HAB}$ monitoring programmes) and not necessarily for climate change studies or climate service development. Difficulties arise when climate models are only available in offshore waters and nearshore areas are unresolved. Key lessons learned in this respect relate to the need for long-term and interconnected environmental monitoring systems, for consistent social science, modeling and statistical expertise in the different cases, and for FAIR (findable, accessible, interoperable and reusable) and open data policies to facilitate data transparency and retrieval.

\section{From Knowledge to Services: Translating Science into Usable Knowledge}

Co-producing actionable, high-quality HAB-climate services through a process that is perceived as meaningful to stakeholders requires consideration of the relevant time-horizons for decision making and managing stakeholder diversity and expectations.

\section{Short-vs. Long-Term Data}

In discussions with stakeholders, it proved useful to conceptually distinguish between short-term and long-term climate service needs. In the short-term, the focus typically lies on mitigating risks associated with specific extreme $\mathrm{HAB}$ events, for which climate services such as improved monitoring and early-warning systems are required. In a longer-term perspective, where the focus is on enhancing resilience and adaptive capacity, a climate service may aim to support ecological and social adaptation to multiple stressors and reduce concurrent anthropogenic pressures on the coastal and ocean environment, such as reduced eutrophication in the Baltic Sea, or reduced coastal development in the Mediterranean.

Overall, most operational stakeholders expressed a preference for short-term information such as real-time, early-warning information or information about potential $\mathrm{HAB}$ developments for the coming season or year. Establishing, maintaining, and enhancing $\mathrm{HAB}$ monitoring systems in the short-term is needed to form a basis for providing "early warnings" of HABs, but could also inform medium- to long-term decisions connected to marine management.

\section{Diverse Stakeholders}

At an early stage of the project, investigations revealed a highly diverse set of stakeholders, ranging from national and local government agencies, to the tourism industry, to individual shellfish farmers and researchers (see also Table 1). The diversity in stakeholder types translated into varying knowledge and capacity, information needs, and different levels of prior or ongoing working relationships between scientists and stakeholders. In some cases, such as in the North/Norwegian sea, this made it difficult to identify a clear direction for developing the content of particular services. To address this complexity, stakeholder mapping exercises were carried out for each of the case studies, using interest/influence matrices (adapted from Mendelow, 1981) to identify appropriate target audiences for the climate services to be co-developed (see Figure 1).

Further, early stakeholder assessments revealed that there was often limited overlap between stakeholders with high influence and high interest in HABs climate services. Notably, efforts to engage government representatives were often time-consuming, partly due to lack of interest in the proposed services. To some extent, this was mitigated by adjusting the methods of stakeholder engagement, for example by switching from larger workshops or online surveys to one-on-one interviews and meetings and regular engagements. In addition, the limited interest in the originally perceived climate services required a change in scientific focus within the project in some cases to better address stakeholder knowledge, interest and concerns. While this was possible in several cases, maintaining flexibility remained a challenge given that the scientific consortium and scientific focus were already to a large degree set.

\section{Managing Stakeholder Expectations}

With generally low TRL levels for the co-developed climate services, managing stakeholder expectations proved a challenge. The knowledge base on HABs was often limited, which required transparent discussions with end-users about limitations, uncertainties, and data resolution, to clarify the potential usefulness and reliability of the climate services as decision-support. Feedback from stakeholders in a number of cases, however, revealed that non-tangible outputs of the co-development process, such as improved relationships, networking, trust, access to scientific expertise and capacity building may be of equal importance as the data and information provided to stakeholders, and constitutes a solid foundation for further science-practice collaborations. 


\section{Interest \& Influence Matrix}

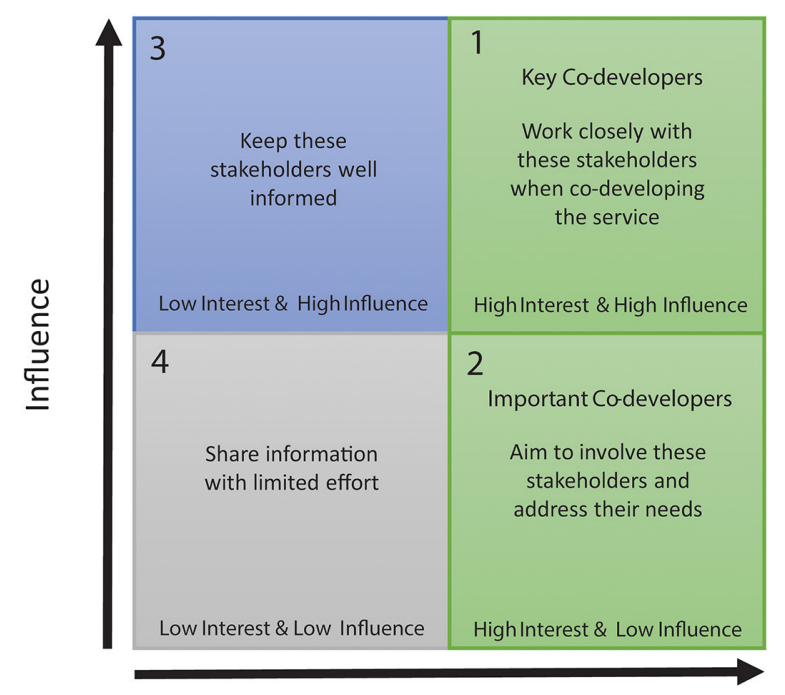

Interest in $\mathrm{HAB}$ climate service
1. High Interest \& High Influence:

Target stakeholders;

"Key Co-developers"

2. High Interest \& Low Influence:

Target stakeholders;

"Important Co-developers"

3. Low Interest \& High Influence:

Stakeholders that should be made

aware of the benefits of climate

service development

4. Low Interest \& Low Influence:

Stakeholders who will be affected

indirectly and/or among whom

interest in a service is currently low

FIGURE 1 | Stakeholder interest-influence matrices were created for each of the case studies. The position of stakeholders in the matrix reflects the identified stakeholder group, their interest in the proposed climate service and their influencing power. Modified version of Mendelow (1981).

Maintaining momentum and stakeholder engagement over the course of the project was also sometimes difficult because the research processes were time-consuming and at times delivered inconclusive results that were not useful to stakeholders. A possible way forward is to focus on enhancing adaptive capacity of ecosystems and institutions to deal with a range of uncertainties, scenarios and changes, irrespective of how specific HABs will develop in the future. Experiences from CoCliME have shown that there is a need to focus on improving or modifying existing services such as HAB monitoring systems, reducing concurrent anthropogenic pressures on the marine environment, such as controlling eutrophication and preventing habitat destruction or modification in coastal areas, as well as focusing on the need to enhance decision-making under uncertainty. Another way forward would be to focus on improving marine planning and governance by placing $\mathrm{HABs}$ in a multi-risk context. In CoCliME's Baltic Sea case study, this was addressed by preparing to integrate $\mathrm{HABs}$ data into a marine spatial planning tool called Symphony, which includes data on a range of human-driven impacts of importance to marine spatial planners, including marine pollution, fishing, shipping, and climate change (Hammar et al., 2020).

Our experiences also point to the value of building on or connecting to pre-existing climate services, to increase their usefulness, narrow the scientific focus, and identify relevant stakeholders. For instance, in the Baltic Sea case study, shifting focus toward a climate service that could feed into an existing marine spatial planning tool clearly ensured interest and reduced the risk of stakeholder fatigue. Another option is to focus on piloting a service on a small scale, to maintain flexibility and ensure that adjustments can be made to meet stakeholder needs. For example, approaches that engaged stakeholders in easy and simple monitoring in coordination with scientists, as conducted to detect Ostreopsis presence and blooms in Mediterranean beaches, proved successful and encouraging.

\section{SUMMARY OF FINDINGS AND IMPLICATIONS FOR THE UN DECADE OF OCEAN SCIENCE}

Lessons learned during the process of implementing the transdisciplinary CoCliME project suggest that progressing and connecting fundamental science with societal needs, understanding the multi-risk decision-making context within which different stakeholders comprehend, appraise and frame $\mathrm{HAB}$ and climate change risks, attending to the shortand long-term aspects of HAB-climate service development, and approaching knowledge co-production in transdisciplinary projects as a learning process are all necessary to generate more salient, legitimate, credible and useful, and usable knowledge. Below, we discuss these key findings and their relevance for enhancing the quality of HAB-climate knowledge and services and addressing key challenges and outcomes that have been prioritized under the UN Decade of Ocean Science for Sustainable development 2021-2030 (UNESCO, 2020), hereafter referred to as "the UN Ocean Decade." 


\section{Understanding the Multi-Risk Decision-Making Context for HAB-Climate Risk Mitigation and Adaptation}

Enhancing community resilience to ocean hazards has been identified as a key priority under the UN Ocean Decade (UNESCO, 2020, p. 11). Findings from CoCliME concur with other studies that understanding the operational, sectoral, social and economic decision-making contexts and capacities in $\mathrm{HAB}$ risk management is essential in order to co-produce high-quality and actionable knowledge to inform societal adaptation decisions (Buontempo et al., 2017). We find that enhancing community resilience to ocean hazards such as HABs requires knowledge of the biology and ecological dynamics of the different harmful organisms, and attention to the different spatial and temporal scales, frequency and severity of harmful impacts and risks faced by diverse stakeholders, regions and sectors. Our findings further show that different stakeholders and scientific disciplines understand, frame and appraise HABs and climate change risks, and adaptation and risk mitigation options in different ways. Developing a shared understanding and framing of the salient problems to be addressed in research involving complex socioecological systems and change processes is a challenge that is widely highlighted in the literature (e.g., Djenontin and Meadow, 2018). The way problems are framed, shapes the approaches to studying them and the solutions generated to address them. Experiences in CoCliME therefore underscore the need for involving stakeholders and their knowledge, and for including mechanisms to facilitate inter- and transdisciplinary communication and understanding, early in the project. These findings echo calls for interdisciplinary and transdisciplinary approaches, broad involvement of stakeholders, and active engagement of social and behavioral sciences in ocean research under the UN Ocean Decade (UNESCO, 2020). They are further in line with those of Dilling and Lemos (2011) and Sarewitz and Pielke (2007) and many others who highlight the importance of stakeholder involvement in knowledge coproduction processes in order to bridge the knowledge-usability gap. Including a strong social science component, investing time in developing interdisciplinary communication and allowing for methodological and ontological pluralism in transdisciplinary projects are additional lessons learned in CoCliME that echo findings from other studies (e.g., Lowe et al., 2013; Klenk and Meehan, 2015) and that should continue to inform scientific efforts under the UN Ocean Decade.

To be credible, salient, and legitimate, decisions concerning investments in basic science, early warning systems, monitoring and various $\mathrm{HAB}$ mitigation and risk management measures should take their starting point in understanding stakeholders' multi-risk decision-making contexts and information needs, the key scientific knowledge gaps, and the expected costs and benefits of implementing different risk mitigation measures (Le Bihan et al., 2013). Acknowledging that enhanced precision and credibility of scientific information does not always translate into immediate or short-term action (Dilling and Lemos, 2011) and that decision-making under uncertainty is the norm in climate adaptation, the costs of investing in different $\mathrm{HAB}$ risk mitigation and adaptation measures need to be weighed against the potential societal risks that HABs pose, and the benefits that high-quality information can provide to different public and private-sector stakeholders (Trainer, 2020).

\section{Need to Progress and Connect the Basic Science With Societal Needs}

The UN Decade of Ocean Science underscores the need for a safe ocean, "where people are protected from ocean hazards" and a predicted ocean, whereby "society has the capacity to understand current and future ocean conditions" (UNESCO, 2020, p. 10). Experiences gained from the co-production processes undertaken in CoCliME highlight that in order to advance the crediblity of HAB-climate services, there is a need for investments in both basic research, and transdisciplinary research to connect HAB-focused marine ecosystem and climate science with society. Despite the progress made within CoCliME to advance scientific understanding of $\mathrm{HAB}$ dynamics, and the consequences and risks for society, large uncertainties and knowledge gaps remain, particularly concerning how climate change may affect these dynamics (Anderson et al., 2019; Wells et al., 2020). Such uncertainties and gaps make it difficult to assess potential future societal exposures, vulnerabilities, and adaptation and mitigation needs, posing challenges to the salience, credibility and legitimacy of future research, stakeholder engagement and service codevelopment efforts.

There is therefore a need to improve basic scientific understanding of HAB-climate links (Griffith and Gobler, 2020). Without a basic foundation of long-term data and observations for generating credible scientific information, the utility of this information for decision-making will remain low (Anderson et al., 2019). High quality, comparable, long-term environmental and $\mathrm{HAB}$ monitoring data are essential to assess and manage $\mathrm{HAB}$ risks over a range of timescales. Monitoring provides the basis to establish and understand long-term environmental and HABs trends, contributes to enhanced basic scientific understanding of $\mathrm{HAB}$ ecology and bloom dynamics, and is necessary to develop "real time" and early warning system information about evolving $\mathrm{HAB}$ risks to the public. Longterm observations of key environmental parameters are needed in order to develop indicators of HAB ecological impacts. Identifying and establishing "supersites" or "sentinel sites" where complete water column (planktonic and benthic) and multidisciplinary monitoring is conducted, and into which $\mathrm{HAB}$ monitoring is integrated, would enable the development of a more complete picture of ecosystem changes and impacts over time and their interactions with multiple climate stressors (Anderson et al., 2019; Griffith and Gobler, 2020).

The increasing imperative of "usability" in sustainability science and in calls for co-production of knowledge (Lemos et al., 2012; Djenontin and Meadow, 2018) therefore needs to be accompanied by progress in more fundamental areas of basic science that are required to establish credible and usable services to meet stakeholder needs. This in turn will require ample time and funding. In CoCliME, it became clear that a 3 year project is insufficient to address basic scientific 
gaps, engage key stakeholders, connect data and knowledge, and develop new HABs-focused services in the novel area of marine ecosystem-focused climate services. For example, a short term (3 day) HAB warning system in Ireland took over 20 years to develop into a scientifically credible and operational programme (Leadbetter et al., 2018). Nonetheless, and echoing the findings reported above, we call for targeted $\mathrm{HAB}$ ecological research and investments in basic science that take their starting point in an understanding of stakeholders' multi-risk decision-making contexts and that address the specific knowledge gaps that are necessary to inform effective mitigation and adaptation strategies to deal with current and emergent $\mathrm{HAB}$ risks.

\section{Need to Focus on Opportunities for Both Short- and Long-Term HAB-Climate Services}

"Delivering data, knowledge and technology for all" and developing early warning systems are highlighted under the UN Ocean Decade (UNESCO, 2020, p. 11). In this respect, the findings from CoCliME suggest that there are multiple avenues and potential entry-points for addressing marine and coastal hazards such as HABs. Engagements between scientists and stakeholders during the project led to the identification of a range of entry-points for prototype $\mathrm{HAB}$-climate services. The first entry-point is to focus on low-hanging fruit such as improving or connecting existing $\mathrm{HAB}$ monitoring services as a basis for short-term $\mathrm{HAB}$ risk mitigation. The second focuses on reducing concurrent and cumulative anthropogenic pressures on the marine environment in order to enhance the adaptive capacity of ecosystems and human societies to respond to multiple stressors. The latter reflects a need that was identified in the project for longer term, adaptive management strategies in coastal regions that take an integrated risk management approach. This approach aims to reduce socio-ecological vulnerability and enhance resilience to concurrent and cumulative human pressures in changing marine environments in order to mitigate $\mathrm{HAB}$ impacts and enhance societal adaptive capacities in the face of marine biological and other hazards. For example, continuing to implement existing policies, including the EU Water Framework Directive and the Marine Strategy Framework, that aim to reduce eutrophication and destructive habitat actions can help to decrease the incidence and consequences of HABs in coastal areas. Integrating $\mathrm{HAB}$ risk management into adaptive management strategies, multi-hazard perspectives and transboundary marine governance frameworks will require connecting high-quality knowledge about HABs to relevant societal and decision-making contexts and integrating and mobilizing knowledge across disciplines, regions, sectors and scales. These findings are relevant for the UN Ocean Decade Challenge 2 which aims to "understand the effects of multiple stressors on ocean ecosystems, and develop solutions to monitor, protect, manage and restore ecosystems and their biodiversity under changing environmental, social and climate conditions" (UN Decade implementation plan 2.0; https://oceanexpert.org/ document/27348).

\section{Need to Approach Knowledge Co-production Processes in Transdisciplinary Projects as a Learning Process}

Lessons learned during the process of implementing the transdisciplinary CoCliME project indicate that generating highquality and actionable HAB-climate services requires dedication as well as realism at the start of a project to determine what can be accomplished when there are large gaps in foundational knowledge upon which HAB-climate services can be built and where the issues and stakeholder needs to be addressed are potentially many. Setting aside ample time to learn about the skills and expertise that different disciplines bring to the project and for developing an in-depth understanding of users' decision-making context and needs would enable identifying and prioritizing key areas of added value for climate service co-development, and novel and innovative ways for scientists and stakeholders to work together. A flexible scientific and management approach with a solid foundation in credible science is important while ensuring sufficient time to build trust, develop shared understandings, and connect and transfer knowledge across disciplines and communities of practice. An appropriate balance between natural and social science expertise (and involvement of communication experts and knowledge brokers) in projects aiming to co-develop marine-focused climate services is further needed in order to enhance the salience, legitimacy and usefulness and usability of the research process and outputs.

Cash et al. (2003) argue that the attributes of salience, credibility and legitimacy are "tightly coupled, such that efforts to enhance any one normally incur a cost to the others" (Cash et al., 2003, p. 8086). Lessons learned in the CoCliME project support this hypothesis. On the one hand, we find that access to long-term environmental and biological datasets, continuous sustained ocean observations and laboratory tests are a basic foundation for generating credible scientific information and for understanding the potential interactions between the effects of climate change on HAB risks and hazards in the future. When combined with an understanding of stakeholders' decisionmaking contexts and priorities, this information can be used as a basis for dialogue about potential future HAB-climate risks and how they might be addressed in the context of wider marine ecosystem changes.

At the same time, establishing long-term monitoring takes time and adequate financing (Anderson et al., 2015). A large body of social science scholarship further shows that improving the availability and quality of knowledge alone will not guarantee its uptake in practice (Lemos and Morehouse, 2005; Lemos et al., 2012). Efforts to reduce scientific knowledge gaps and uncertainties about HAB-climate linkages (efforts to enhance credibility) therefore need to be accompanied by more holistic efforts to reduce societal vulnerability and support adaptation to $\mathrm{HAB}$, climate and other concurrent risks facing coastal and marine environments, where there are high stakes and high uncertainties on both the social and environmental sides (Cvitanovic et al., 2015; Whitney et al., 2017). 
All of these lessons are relevant for, and should inform, the implementation of the UN Ocean Decade. Making progress toward addressing these lessons will require open-mindedness, a commitment to transdisciplinarity and involving appropriate scientific and stakeholder expertise. Building conceptual, methodological and organizational flexibility into projects is essential to encourage iteration and capacity building and to incentivize the creation of products and services that suit evolving stakeholder needs and priorities. Since most scientists are not trained in conducting holistic assessments of coupled socio-ecological coastal and marine systems (Stenseth et al., 2020), this will require broader transformations in the organization, funding and incentive structures in marine science and education akin to those that are called for in order to address the societal challenges posed by climate change (Fazey et al., 2020; Shrivastava et al., 2020). In addition, it will require overcoming "fear of failure" and documenting and sharing not only project successes, but also key lessons learned about what "did not work" (Catalano et al., 2019).

To conclude, CoCliME contributed to the main pillars of the UN Ocean decade by inter alia, co-developing highquality, interdisciplinary, science-based knowledge on HAB risks in Europe, providing tools for understanding and modeling $\mathrm{HAB}$ trends and understanding their potential societal and ecological impacts under climate change, undertaking capacity building activities, and connecting science and society toward the sustainable management and use of coastal and ocean resources. The lessons learned while implementing this pilot European project should help to inform and progress transdisciplinary research practices toward improving the health and well-being of our ocean and societies; working toward getting "The Science we need" for "The Ocean we want" in the UN Decade of Ocean Science.

\section{REFERENCES}

Anderson, C. R., Berdalet, E., Kudela, R. M., Cusack, C., Silke, J., O’Rourke, E., et al. (2019). Scaling up from regional case studies to a global harmful algal bloom observing system. Front. Mar. Sci. 6:250. doi: 10.3389/fmars.2019.00250

Anderson, C. R., Moore, S., Tomlinson, M., Silke, J., and Cusack, C. (2015). "Chapter 17 Living With harmful algal blooms in a changing world: strategies for modeling and mitigating their effects in coastal marine ecosystems," in Coastal and Marine Hazards, Risks, and Disasters, eds J. F. Shroder, J. T. Ellis, and D. J. Sherman (Boston, MA: Elsevier), 495-561. doi: 10.1016/b978-0-12-396483-0.00017-0

Berdalet, E., Fleming, L. E., Gowen, R., Davidson, K., Hess, P., Backer, L. C., et al. (2016). Marine harmful algal blooms, human health and wellbeing: challenges and opportunities in the 21st century. J. Mar. Biol. Assoc. 96(Special Issue 01), 61-96. doi: $10.1017 / \mathrm{S} 0025315415001733$

Bindoff, N. L., Cheung, W. W. L., Kairo, J. G., Arístegui, J., Guinder, V. A., Hallberg, R., et al. (2019). "Changing ocean, marine ecosystems, and dependent communities," in IPCC Special Report on the Ocean and Cryosphere in a Changing Climate, eds H.-O. Pörtner, D. C. Roberts, V. Masson-Delmotte, P. Zhai, M. Tignor, E. Poloczanska, et al. Available online at: https://www.ipcc.ch/ srocc/chapter/chapter-5/

Buontempo, C., Hanlon, H. M., Soares, M. B., Christel, I., Soubeyroux, J.-M., Viel, C., et al. (2017). What have we learned from EUPORIAS climate service prototypes? Clim. Serv. 9, 21-32. doi: 10.1016/j.cliser.2017.06.003

\section{DATA AVAILABILITY STATEMENT}

The data analyzed in this study are subject to the following licenses/restrictions: Requests to access datasets related to this publication should be directed to caroline.cusack@marine.ie.

\section{AUTHOR CONTRIBUTIONS}

JW and EB contributed to conceptualizing the research project and to leading various project work packages. CC led and managed the project consortium and coordinated the overall project deliverables. JW drafted the paper. All authors contributed to conceptualizing the paper, gathering and analyzing data, and writing, reviewing, and improving the final manuscript.

\section{FUNDING}

Project CoCliME is part of ERA4CS, an ERA-NET initiated by JPI Climate, and funded by EPA (IE), ANR (FR), BMBF (DE), UEFISCDI (RO), RCN (NO), and FORMAS (SE), with co-funding by the European Union (Grant 690462). CoCliME is endorsed by the International Programme of IOC UNESCO and SCOR GlobalHAB (www.globalhab.info).

\section{ACKNOWLEDGMENTS}

The authors would like to thank Seamus Heffernan (Marine Institute) for actively contributing to the discussions informing this paper and for his help with collecting and collating various project lessons learned. EB received institutional support from the Severo Ochoa Centre of Excellence accreditation (CEX2019000928-S).

Cash, D., Clark, W. C., Alcock, F., Dickson, N. M., Eckley, N., and Jäger, J. (2002) Salience, credibility, legitimacy and boundaries: linking research, assessment and decision making. KSG Working Papers Series, 2002. Available online at: https://ssrn.com/abstract $=372280$

Cash, D. W., Clark, W. C., Alcock, F., Dickson, N. M., Eckley, N., and Guston, D. H., et al. (2003) Knowledge systems for sustainable development. PNAS 100, 8086-8091. doi: 10.1073/pnas.1231332100

Catalano, A. S., Lyons-White, J., Mills, M. M., and Knight, A. T. (2019). Learning from published project failures in conservation. Biol. Conserv. 238:108223. doi: 10.1016/j.biocon.2019.108223

Claudet, J., Bopp, L., Cheung, W. W. L., Devillers, R., Escobar-Briones, E., Haugan, P., et al. (2020). A roadmap for using the UN decade of ocean science for sustainable development in support of science, policy, and action. One Earth 2, 34-42. doi: 10.1016/j.oneear.2019.10.012

Cvitanovic, C., Hobday, A. J., van Kerkhoff, L., Wilson, S. K., Dobbs, K., and Marshall, N. A. (2015). Improving knowledge exchange among scientists and decision-makers to facilitate the adaptive governance of marine resources: a review of knowledge and research needs. Ocean Coastal Manage. 112, 25-35. doi: 10.1016/j.ocecoaman.2015.05.002

Di Lorenzo, E., and Mantua, N. (2016). Multi-year persistence of the 2014/15 North Pacific marine heatwave. Nat. Clim. Change 6, 1042-1047. doi: $10.1038 /$ nclimate3082

Dilling, L., and Lemos, M. C. (2011). Creating usable science: opportunities and constraints for climate knowledge use and their implications for science 
policy. Global Environ. Change 21, 680-689. doi: 10.1016/j.gloenvcha.2010. 11.006

Djenontin, I. N. S., and Meadow, A. M. (2018). The art of coproduction of knowledge in environmental sciences and management: lessons from international practice. Environ. Manage 61, 885-903. doi: 10.1007/s00267-018-1028-3

Engle, N. L. (2011). Adaptive capacity and its assessment. Glob. Environ. Change 21, 647-656. doi: 10.1016/j.gloenvcha.2011.01.019

European Marine Board (2013). Linking oceans and human health: a strategic research priority for Europe. Position Paper 19 EMB (Ostend).

European Parliament (2015). Ocean Research in Horizon 2020: The Blue Growth Potential. Policy Department A: Economic and Scientific Policy. European Parliament. IP/A/ITRE/2014-7. PE 518.775.

Fazey, I., Schäpke, N., Caniglia, G., Hodgson, A., Kendrick, I., Lyon, C., et al. (2020). Transforming knowledge systems for life on Earth: visions of future systems and how to get there. Energy Res. Soc. Sci. 70:101724. doi: 10.1016/j.erss.2020.101724

Field, C. B., Barros, V. R., Mach, K. J., Mastrandrea, M. D., van Aalst, M., Adger, W. N., et al. (2014) "Technical summary," in Climate Change 2014: Impacts, Adaptation, and Vulnerability. Part A: Global and Sectoral Aspects. Contribution of Working Group II to the Fifth Assessment Report of the Intergovernmental Panel on Climate Change, eds C. B. Field, V. R. Barros, D. J. Dokken, K. J. Mach, M. D. Mastrandrea, T. E. Bilir (Cambridge; New York, NY: Cambridge University Press), 35-94.

Gaillard, S., Charrier, A., Malo, F., Carpentier, L., Bougaran, G., Hégaret, H., et al. (2020) Combined effects of temperature, irradiance, and $\mathrm{pH}$ on Teleaulax amphioxeia (Cryptophyceae) physiology and feeding ratio for its predator Mesodinium rubrum (Ciliophora). J. Phycol. 56, 775-783. doi: $10.1111 /$ jpy. 12977

Gallardo-Rodríguez, J. J., Astuya-Villalón, A., Llanos-Rivera, A., Avello-Fontalba, V., and Ulloa-Jofré, V. (2019). A critical review on control methods for harmful algal blooms. Rev. Aquacult. 11, 661-684. doi: 10.1111/raq.12251

GEOHAB (2001). Global Ecology of Harmful Algal Blooms, Science Plan, eds P. Glibert and G. Pitcher (Baltimore, MD; Paris: SCOR and IOC), 87. Available online at: https://www.globalhab.info

GlobalHAB (2017). Global Harmful Algal Blooms, Science and Implementation Plan, eds E. Berdalet, N. Banas, E. Bresnan, M. Burford, K. Davidson, C. Gobler (Paris: SCOR and IOC), 64. Available online at: www.globalhab.info

Gobler, C. J. (2020). Climate change and harmful algal blooms: insights and perspective. Harmful Algae 91:101731. doi: 10.1016/j.hal.2019.101731

Griffith, A. W., and Gobler, C. J. (2020). Harmful algal blooms: a climate change co-stressor in marine and freshwater ecosystems. Harmful Algae 91:101590. doi: 10.1016/j.hal.2019.03.008

Guillotreau, P., Allison, E. H., Bundy, A., Cooley, S. R., Defeo, O., Le Bihan, V., et al. (2017). A comparative appraisal of the resilience of marine social-ecological systems to mass mortalities of bivalves. Ecol. Soc. 22:46. doi: 10.5751/ES-09084-220146

Hallegraeff, G. M. (2010). Ocean climate change, phytoplankton community responses, and harmful algal blooms: a formidable predictive challenge. J. Phycol. 46, 220-235. doi: 10.1111/j.1529-8817.2010.00815.x

Hammar, L., Molander, S., Pålsson, J., Crona, J. S., Carneiro, G., Johansson, T., et al. (2020). Cumulative impact assessment for ecosystem-based marine spatial planning. Sci. Tot. Environ. 734:139024. doi: 10.1016/j.scitotenv.2020.1 39024

IPCC. (2014). "Climate change 2014: synthesis report," in Contribution of Working Groups I, II and III to the Fifth Assessment Report of the Intergovernmental Panel on Climate Change, eds Core Writing Team, R. K. Pachauri, and L. A. Meyer (Geneva: IPCC), 151.

Klenk, N., and Meehan, K. (2015). Climate change and transdisciplinary science: problematizing the integration imperative. Environ. Sci. Policy 54, 160-167. doi: 10.1016/j.envsci.2015.05.017

Kudela, R. M., Berdalet, E., Bernard, S., Burford, M., Fernand, L., Lu, S., et al. (2015). Harmful Algal Blooms. A Scientific Summary for Policy Makers. Paris: IOC/UNESCO (IOC/INF-1320).

Le Bihan, V., Pardo, S., and Guillotreau, P. (2013). Risk perception and risk management strategies of oyster farmers. Mar. Resour. Econ. 28, 285-304. doi: 10.5950/0738-1360-28.3.285
Leadbetter, A. M., Silke, J., and Cusack, C. (2018). Creating a Weekly Harmful Algal Bloom Bulletin. Galway: Marine Institute, 59.

Leichenko, R., and O'Brien, K. (2000). Double exposure: assessing the impacts of climate change within the context of economic globalization. Glob. Environ. Change 10, 221-232. doi: 10.1016/S0959-3780(00)00021-2

Lemos, M. C., Kirchhoff, C. J., and Ramprasad, V. (2012). Narrowing the climate information usability gap. Nat. Clim. Change 2, 789-794. doi: 10.1038/nclimate1614

Lemos, M. C., and Morehouse, B. J. (2005). The co-production of science and policy in integrated climate assessments. Glob. Environ. Change 15, 57-68. doi: 10.1016/j.gloenvcha.2004.09.004

Lowe, P., Phillipson, J., and Wilkinson, K. (2013). Why social scientists should engage with natural scientists. Contemp. Soc. Sci. 8, 207-222. doi: $10.1080 / 21582041.2013 .769617$

Lugen, M. (2020). Framing climate services: logics, actors, and implications for policies and projects. Atmosphere 11:1047. doi: 10.3390/atmos11101047

McCabe, R. M., Hickey, B. M., Kudela, R. M., Lefebvre, K. A., Adams, N. G., Bill, B. D., et al. (2016). An unprecedented coastwide toxic algal bloom linked to anomalous ocean conditions. Geophys. Res. Lett. 43, 10366-10376. doi: 10.1002/2016GL070023

Mendelow, A. L. (1981). Environmental Scanning - The Impact of the Stakeholder Concept. ICIS, 20. Available online at: https://aisel.aisnet.org/icis1981/20

Pearlman, J. S., Bushnell, M., Coppola, L., Buttigieg, P. L., Pearlman, F., Simpson, P., et al. (2019). Evolving and sustaining ocean observing best practices and standards fostering interoperability for the next decade of science and policy. Front. Mar. Sci. 6:277. doi: 10.3389/fmars.2019.00277

Pörtner, H.-O., Roberts, D. C., Masson-Delmotte, V., Zhai, P., Tignor, M., Poloczanska, E., et al. (2019). IPCC Special Report on the Ocean and Cryosphere in a Changing Climate. Available online at: https://www.ipcc.ch/srocc/

Raine, R. (2014). A review of the biophysical interactions relevant to the promotion of HABs in stratified systems: the case study of Ireland. Deep Sea Res. II 101, 21-31. doi: 10.1016/j.dsr2.2013.06.021

Ralston, D. K., and Moore, S. K. (2020). Modeling harmful algal blooms in a changing climate. Harmful Algae 91:101729. doi: 10.1016/j.hal.2019.101729

Ritzman, J., Brodbeck, A., Brostrom, S., McGrew, S., Dreyer, S., Klinger, T., et al. (2018). Economic and sociocultural impacts of fisheries closures in two fishing-dependent communities following the massive 2015 U.S. West Coast harmful algal bloom. Harmful Algae 80, 35-45. doi: 10.1016/j.hal.2018. 09.002

Roberts, S. D., Van Ruth, P. D., Wilkinson, C., Bastianello, S. S., and Bansemer, M. S. (2019). Marine heatwave, harmful algae blooms and an extensive fish kill event during 2013 in South Australia. Front. Mar. Sci. 6:610. doi: 10.3389/fmars.2019.00610

Sarewitz, D., and Pielke, R. A. Jr. (2007). The neglected heart of science policy: reconciling supply of and demand for science. Environ. Sci. Policy 10, 5-16. doi: 10.1016/j.envsci.2006.10.001

Shrivastava, P., Stafford Smith, M., O’Brien, K., and Laszlo, Z. (2020). Transforming sustainability science to generate positive social and environmental change globally. One Earth 2, 329-340. doi: 10.1016/j.oneear.2020.04.010

Smayda, T. J. (1997). What is a bloom? A commentary. Limnol. Oceanogr. 42, 1132-1136. doi: 10.4319/lo.1997.42.5_part_2.1132

Smit, B., and Wandel, J. (2006). Adaptation, adaptive capacity and vulnerability. Glob. Environ. Change 16, 282-292. doi: 10.1016/j.gloenvcha.2006.03.008

Stenseth, N. C., Payne, M. R., Bonsdorff, E., Dankel, D. J., Durant, J. M., Anderson, L. G., et al. (2020). Attuning to a changing ocean. PNAS 17, 20363-20371. doi: 10.1073/pnas.1915352117

Trainer, V. L. (Ed.). (2020). GlobalHAB: Evaluating, Reducing and Mitigating the Cost of Harmful Algal Blooms: A Compendium of Case Studies. PICES Scientific Report No. 59. ISBN 978-1-927797-40-2.

Trainer, V. L., Bates, S. S., Lundholm, N., Thessen, A. E., Cochlan, W. P., Adams, N. G., et al. (2012). Pseudo-nitzschia physiological ecology, phylogeny, toxicity, monitoring and impacts on ecosystem health. Harmful Algae 14, 271-300. doi: 10.1016/j.hal.2011.10.025

Trainer, V. L., Kudela, R. M., Hunter, M. V., Adams, N. G., and McCabe, R. M. (2020a). Climate extreme seeds a new domoic acid hotspot on the US west coast. Front. Clim. 2:571836. doi: 10.3389/fclim.2020.571836 
Trainer, V. L., Moore, S. K., Hallegraeff, G., Kudela, R. M., Clement, A., Mardones, J. I., et al. (2020b). Pelagic harmful algal blooms and climate change: lessons from nature's experiments with extremes. Harmful Algae 91:101591. doi: 10.1016/j.hal.2019.03.009

UNESCO (2020). The Science We Need for the Ocean We Want: The United Nations Decade of Ocean Science for Sustainable Development (2021-2030). Paris. IOC Brochure 2020-4 (IOC/BRO/2020/4). Available online at: https:// www.oceandecade.org/

Vila, M., Abós-Herràndiz, R., Isern-Fontanet, J., Àlvarez, J., and Berdalet, E. (2016). Establishing the link between Ostreopsis cf. ovata blooms and human health impacts using ecology and epidemiology. Sci. Mar. 80, 107-115. doi: 10.3989/scimar.04395.08A

Wells, M. L., Karlson, B., Wulff, A., Kudela, R., Trick, C., Asnaghi, V., et al. (2020). Future HAB Science: directions and challenges in a changing climate. Harmful Algae 91:101632, doi: 10.1016/j.hal.2019.101632

Wells, M. L., Trainer, V. L., Smayda, T. J., Karlson, B. S. O., Trick, C. G., Kudela, R. M., et al. (2015). Harmful algal blooms and climate change: learning from the past and present to forecast the future. Harmful Algae 49, 68-93. doi: 10.1016/j.hal.2015.07.009

Whitney, C., Bennett, N. J., Ban, N. C., Allison, E. H., Armitage, D., Blythe, D., et al. (2017). Adaptive capacity: from assessment to action in coastal socio-ecological systems. Ecol. Soc. 22:22. doi: 10.5751/ES-09325-2 20222

Willisa, C., Papathanasopouloub, E., Russela, D., and Artiolib, Y. (2018). Harmful algal blooms: the impacts on cultural ecosystem services and human wellbeing in a case study setting, Cornwall, UK. Mar. Policy 97, 232-238. doi: 10.1016/j.marpol.2018.06.002

Conflict of Interest: The authors declare that the research was conducted in the absence of any commercial or financial relationships that could be construed as a potential conflict of interest.

The reviewer SM declared a past co-authorship with the authors EB and CC to the handling editor.

Copyright (C) 2021 West, Järnberg, Berdalet and Cusack. This is an open-access article distributed under the terms of the Creative Commons Attribution License (CC BY). The use, distribution or reproduction in other forums is permitted, provided the original author(s) and the copyright owner(s) are credited and that the original publication in this journal is cited, in accordance with accepted academic practice. No use, distribution or reproduction is permitted which does not comply with these terms. 